\title{
Estratégias de valorização e divulgação de geomorfossítios da microrregião de Picos (Piauí), com vistas a sua utilização pelo geoturismo
}

\author{
Estrategias de valorización y divulgación de geomorfositios de \\ la microrregión de Picos (Piauí), con vistas a su utilización por \\ el geoturismo
}

\section{Strategies for the valorization and dissemination of geomorphosites of the microregion of Picos (Piauí) aiming their use for geotourism}

\author{
José Francisco de Araújo Silva \\ jfaraujo6@hotmail.com \\ Universidade Federal do Piauí, UFPI, Teresina, PI \\ Hikaro Kayo de Brito Nunes \\ hikarokayo2@hotmail.com \\ Universidade Estadual do Maranhão - CESC/LEMA, São Luis, MA \\ Cláudia Maria Sabóia de Aquino \\ cmsaboia@gmail.com \\ Universidade Federal do Piauí, UFPI, Teresina, PI
}

\begin{abstract}
Resumo: Sustentado na visão de que se torna necessário a elaboração de ações para preservação e disseminação de informações relacionadas a áreas com grande importância geológica e geomorfológica, o estudo que se segue tem como objetivo apresentar estratégias de valorização e divulgação dos potenciais geomorfossítios localizados na microrregião de Picos, no estado do Piauí. A metodologia foi pautada em atividades de gabinete e de campo, utilização do Google Earth e de programas de computador para a confecção e design gráfico das estratégias selecionadas. Isto posto, os cinco geomorfossítios analisados receberam as seguintes estratégias: roteiro geológicogeomorfológico (geoturístico), painéis informativos e interpretativos, folders, guias de bolso, cartões-postais, websites e contas em redes sociais e geoprodutos (chaveiros e squeeze).
\end{abstract}

Palavras-chave: Geopatrimônio, geoconservação, disseminação.

Resumen: Sostenido en la visión de que se hace necesario la elaboración de acciones para preservación y diseminación de informaciones relacionadas a áreas con gran importancia geológica y geomorfológica, el estudio que sigue tiene como objetivo presentar estrategias de valorización y divulgación de los potenciales geomorfositios ubicados en la microrregión de Picos, en el estado de Piauí. La metodología fue pautada en actividades de gabinete y de campo, utilización de Google Earth y de programas de ordenador para la confección y diseño gráfico de las estrategias seleccionadas. En este sentido, los cinco geomorfostios analizados recibieron las siguientes 
estrategias: itinerario geológico-geomorfológico (geoturístico), paneles informativos e interpretativos, carpetas, guías de bolsillo, tarjetas postales, sitios web y cuentas en redes sociales y geoproductos (llaveros y squeeze).

Palabras-clave: Geopatrimônio, geoconservación, difusión

\begin{abstract}
Taking into account that it is necessary to elaborate actions for the preservation and dissemination of information related to areas of great geological and geomorphological importance, this study aims to present strategies of valorization and dissemination of potential geomorphosites located in the Picos microregion in the state of Piauí. The methodology was based on office and field activities, use of Google Earth and computer programs for the design and graphic design of selected strategies. To the five geomorphosites, it was provided geological geomorphological guides, informative and interpretative panels, folders, pocket guides, postcards, websites, accounts in social networks, and geoproducts (key chains and squeeze).
\end{abstract}

Keywords: Geopatrimony, geoconservation, dissemination.

\title{
INTRODUÇÃO
}

Em razão da rica natureza abiótica do planeta e os riscos aos quais está exposta, principalmente no que concerne à degradação, decorrente, em muitos casos, do desconhecimento do patrimônio natural, bem como da importância deste, torna-se necessário conservar a parte da geodiversidade que apresente valores excepcionais, sejam científicos, turísticos, estéticos ou outros. Notadamente no que se refere à sua importância para a humanidade e para a compreensão dos processos geológicos e geomorfológicos existentes na Terra, de modo que as áreas dotadas de valores excepcionais tenham medidas de geoconservação.

Brilha (2005) sugere a seguinte sequência metodológica para a elaboração de estratégias de geoconservação: inventariação, quantificação, classificação, conservação, valorização e divulgação, e monitoramento. Meira (2016) aponta que essas estratégias são detentoras de grande importância nas pesquisas sobre geopatrimônio, posto estabelecerem aproximação do público em geral com distintos conceitos tais como: geodiversidade e patrimônio geomorfológico.

Considerando a importância de se compreender e valorizar o patrimônio geomorfológico, sobre o qual se entende os elementos geomorfológicos, de variadas dimensões, possuidores de um ou mais tipos de valor e que precisam ser protegidos e valorizados (PEREIRA, 2006), o objetivo deste estudo é apresentar estratégias de valorização e divulgação dos potenciais geomorfossítios identificados em estudo de Silva et al. (2017) no âmbito da Microrregião de Picos (estado do Piauí), conforme Figura 1. As estratégias aqui apresentadas estão pautadas, sobretudo, na utilização dos geomorfossítios pela atividade turística (geoturismo), uma vez que o mesmo pode ser uma medida eficaz de geoconservação. 
Figura 1 - Localização da área de estudo.
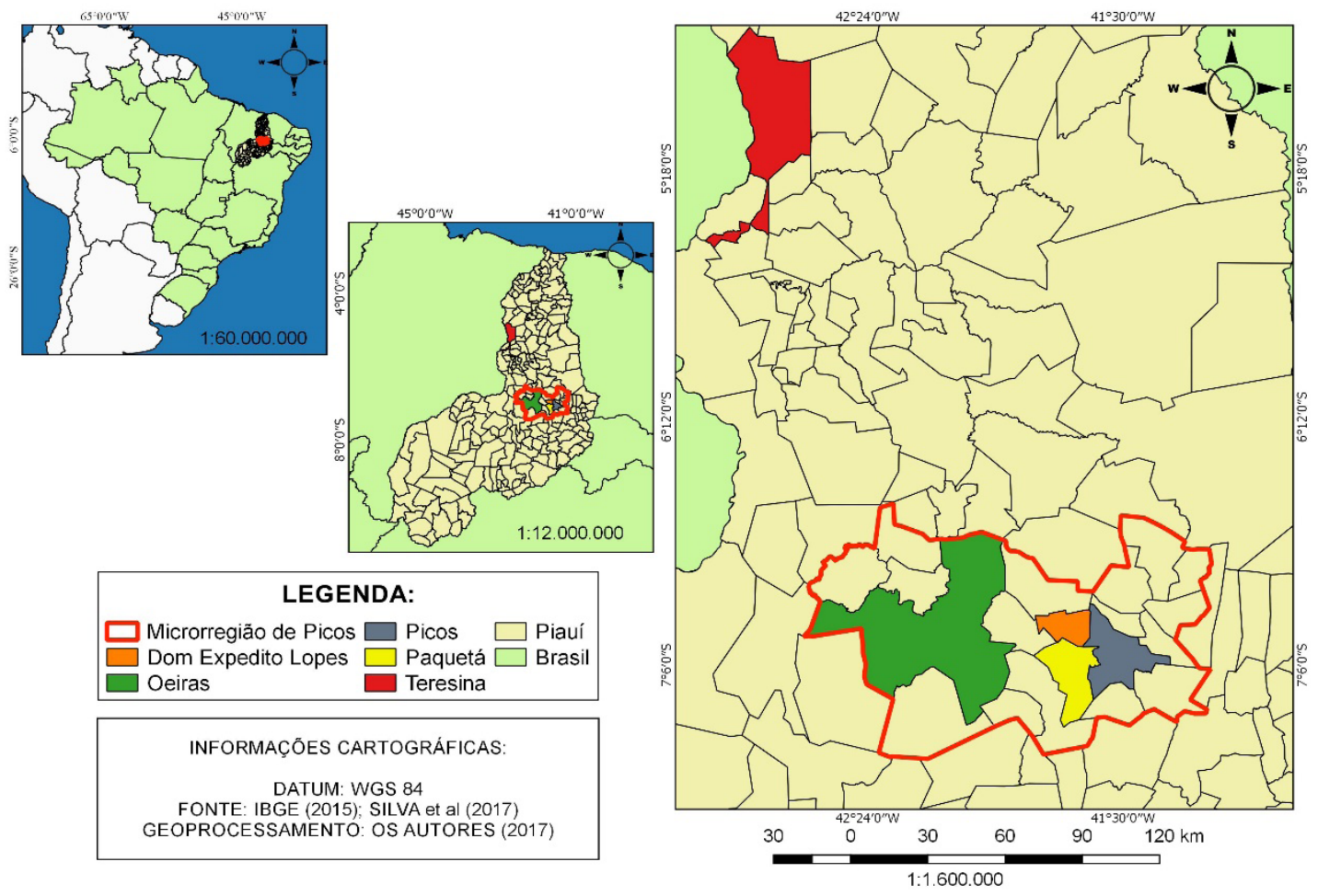

Fonte: os autores.

A área de estudo está inserida na mesorregião Sudeste do Piauí, no Território de Desenvolvimento Vale do Guaribas e dista aproximadamente $310 \mathrm{~km}$ da capital, Teresina, tendo como escala de distância a relação com a cidade de Picos.

\section{BREVES CONSIDERAÇÕES CONCEITUAIS}

Com o gradativo aumento da tomada de consciência sobre as questões ambientais, torna-se de fundamental importância a elaboração de mecanismos e/ou estratégias que possibilitem uma valorização dos recursos e meios de ordem natural. Nesse sentido, o geoturismo atua como importante meio de valorização e proteção do meio natural, quer seja no seu caráter científico, quer seja no seu caráter de ordenamento de acesso/uso a determinadas áreas, as quais são denominadas nesse estudo de geomorfossítios, por considerar o relevo da área como elemento dotado de valores científico, cultural, estético, entre outros. Ressalta-se que o modelado do relevo local destaca-se frente aos demais elementos da geodiversidade presentes, o que favorece a sua classificação como geomorfossítio.

Moura-Fé (2015, p. 53) argumenta que o geoturismo se caracteriza como um segmento "promissor da atividade turística, relacionado ao ecoturismo, com características específicas e essenciais à conservação da geodiversidade, em consonância com diversos preceitos exigidos para o desenvolvimento econômico" das comunidades em que há o desenvolvimento dessa atividade. 
Godoy (2013) afirma que a geodiversidade deve ser considerada como um testemunho científico dos acontecimentos pretéritos que marcaram a história evolutiva do planeta Terra, devendo, assim, ser conservada como parte intrínseca do patrimônio natural e utilizada para meios científicos, didáticos e culturais. Desse modo, com base na relevância da geodiversidade em diferentes contextos em que está inserida, cabe, como já mencionado, ações geoturísticas de maneira a popularização dessa relevância e sua preservação.

As discussões sobre a necessidade de preservar/repensar a temática ambiental têm ganhado força de várias áreas do conhecimento, principalmente no final do século XX, deixando-a cada vez mais interdisciplinar, principalmente quando da tomada de consciência sobre a degradação e limitação do meio. No que se refere às áreas geoturísticas, pode ocorrer também apreciação da paisagem e espetacularidade cênica, atividades de geoconservação, desenvolvimento local, mitigação de impactos ambientais e usos científicos. A inter-relação existente entre geoturismo, geoconservação, geoparque, desenvolvimento sustentável e educação (Fig. 2) tem o papel de proporcionar a manutenção do patrimônio e os benefícios resultantes tanto a nível local quanto a nível regional, principalmente quando aproximadas as esferas sociais, econômicas, ambientais, culturais e educacionais no bojo da discussão.

Figura 2 - Inter-relações do geoturismo

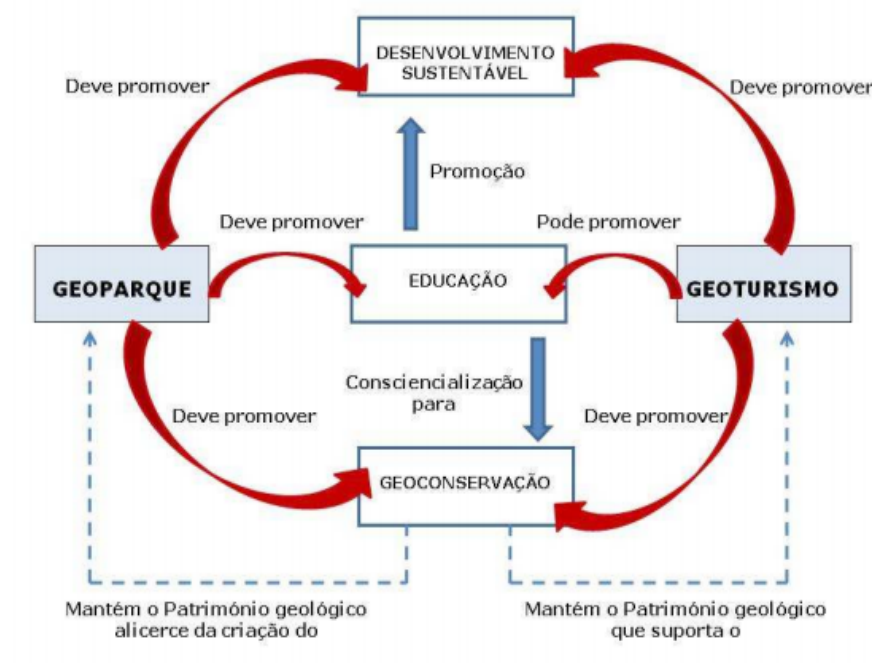

Fig. 2.3 - Inter-relações que se podem estabelecer entre os objectivos de criação de um geoparque e as consequências das actividades geoturísticas.

Fonte: Vasquez (2010)

Como forma de agregar valor e propagar esses geomorfossítios dentro da contribuição de diversos autores, há a proposição de diversas estratégias de valorização e divulgação do patrimônio geológico - áreas de caráter excepcional no que se refere às suas particularidades cênicas e fisiográficas, e dos aspectos culturais e econômicos presentes. Machado e Ruchkys (2010), ao discutirem o Programa Rocha Amiga, uma estratégia específica de valorização e divulgação da geodiversidade por meio de atividades educativas em Minas Gerais (MG) afirmam que 
Foi criado com o objetivo de criar um espaço para o desenvolvimento de atividades, produção de materiais didáticos e novas abordagens que contribuam para a inovação do ensino das geociências, [...] este projeto sensibilizou alunos do ensino fundamental para o papel das geociências na sociedade contemporânea, tendo como estratégia a divulgação da função que as rochas desempenham para o bem-estar e desenvolvimento sustentado das populações (MACHADO; RUCHKYS, 2010, p. 55).

O destaque que as autoras dão ao conhecimento sobre as rochas, seu contexto evolutivo e sua importância para o público ratifica bons resultados que demandam da geoconservação e do geoturismo. Em outro cenário, Garcia (2014) indica estratégias para a o município gaúcho de Caçapava do Sul, com destaque para rotas de escalas de feições geológicas, folders e painéis. Por sua vez, Oliveira (2015), ao propor estratégias de divulgação e valorização em Coromandel e Vazante (Minas Gerais), elenca guia de bolso, placa informativa, cartão postal, folders, trilhas, painéis interpretativos, trilha ecológica, criação de um ambiente virtual e um centro de visitantes.

\section{METODOLOGIA}

Os procedimentos metodológicos compreenderam levantamento e análise teórica, pesquisa de campo, registro fotográfico, uso de imagens de satélite disponíveis no Google Earth e o uso de softwares (Corel Draw e Power Point, ambos com licença) para a confecção e o design gráfico (principalmente relacionados à cor, contraste, nitidez e realce) das estratégias de valorização e divulgação (Fig. 3).

Figura 3 - Mosaico das interfaces dos programas utilizados para a confecção e design gráfico das estratégias de valorização e divulgação.

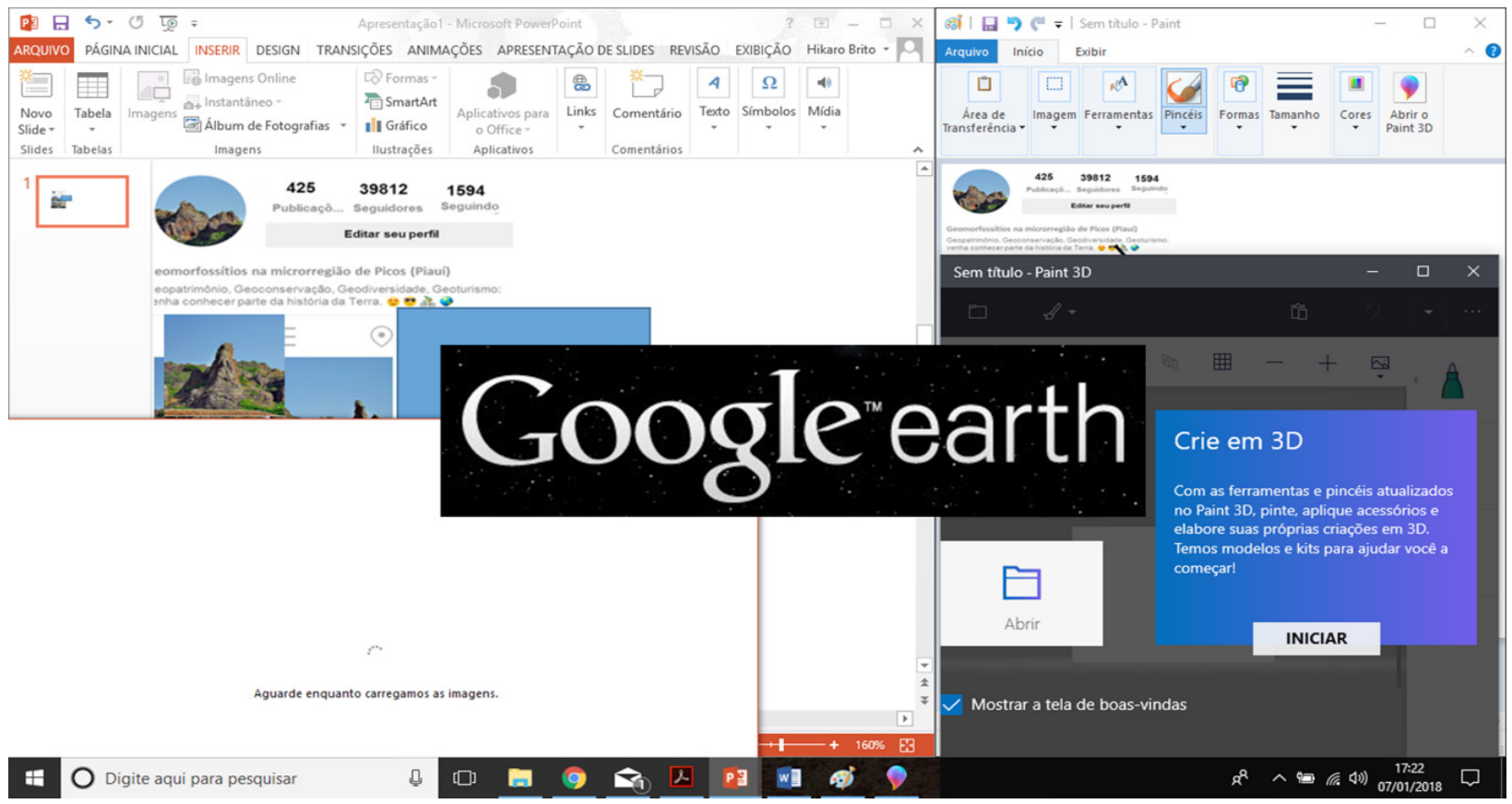

Fonte: os autores. 
Nesse estudo são apresentadas estratégias de valorização e divulgação para os geomorfossítios categorizados nas classes de Médio e Alto Potencial Educativo e Turístico de acordo com a metodologia de Oliveira (2015). Os cinco geomorfossítios aptos a receberem as estratégias de conservação são: Morro do Leme (munícipio de Oeiras/Piauí), Furna da Quitéria e Alpes "O buriti” (ambos no munícipio de Dom Expedito Lopes/Piauí), Sucavão (munícipio de Paquetá do Piauí/Piauí) e Afloramento de diabásio (munícipio de Picos/PI).

Para a elaboração das estratégias, foram consideradas as propostas de Moreira (2008), Lopes (2011), Guimarães (2013), Piekarz e Liccardo (2014), Silva e Baptista (2014), Oliveira (2015), Meira (2016) e Santos (2016).

Foram consideradas as seguintes estratégias: roteiro geológico-geomorfológico (geoturístico), painéis informativos e interpretativos, folders, guias de bolso, cartões-postais, websites e contas em redes sociais, além de geoprodutos (chaveiros e squeeze), as quais deverão ser desenvolvidas pelos agentes públicos (gestores) dos municípios, bem como lideranças locais de cada área (presidentes de ONGs e associações de moradores, por exemplo) em que estão localizados os geomorfossítios anteriormente elencados e no caso daqueles que estão presentes em áreas particulares, através de parceria público-privada.

\section{RESULTADOS E DISCUSSÃO}

O quadro 1 resume as propostas de estratégias de valorização e divulgação dos geomorfossítio identificados na microrregião de Picos, Piauí. Destaca-se que o roteiro geoturístico (geológico-geomorfológico), o website e os perfis em redes sociais, foram pensados para serem aplicados de modo unificado.

Quadro 1 - Estratégias de valorização e divulgação dos geomorfossítios na microrregião de Picos/PI

\begin{tabular}{|l|c|c|c|c|c|}
\hline \multicolumn{1}{c}{ ESTRATÉGIAS } & \multicolumn{5}{c|}{ GEOMORFOSSÍTIOS } \\
\cline { 2 - 6 } & Morro do Leme & $\begin{array}{c}\text { Furna da } \\
\text { Quitéria }\end{array}$ & $\begin{array}{c}\text { Alpes "O } \\
\text { buriti" }\end{array}$ & $\begin{array}{c}\text { Sucavão } \\
\text { Afloramento de } \\
\text { diabásio }\end{array}$ \\
\hline Roteiro geoturístico & $\mathrm{X}$ & $\mathrm{X}$ & $\mathrm{X}$ & $\mathrm{X}$ & $\mathrm{X}$ \\
\hline Painéis & $\mathrm{X}$ & $\mathrm{X}$ & - & - & $\mathrm{X}$ \\
\hline Folders e guias de bolso & - & $\mathrm{X}$ & $\mathrm{X}$ & $\mathrm{X}$ & - \\
\hline Cartões-postais & $\mathrm{X}$ & - & $\mathrm{X}$ & $\mathrm{X}$ & - \\
\hline Chaveiros & $\mathrm{X}$ & - & $\mathrm{X}$ & - & $\mathrm{X}$ \\
\hline Squeeze & - & $\mathrm{X}$ & $\mathrm{X}$ & $\mathrm{X}$ & - \\
\hline Websites & $\mathrm{X}$ & $\mathrm{X}$ & $\mathrm{X}$ & $\mathrm{X}$ & \\
\hline Contas em redes sociais & $\mathrm{X}$ & $\mathrm{X}$ & $\mathrm{X}$ & $\mathrm{X}$ & $\mathrm{X}$ \\
\hline
\end{tabular}

Fonte: os autores

Salienta-se ainda que o conjunto de estratégias podem ser aplicadas em todos os geomorfossítios, contudo, as propostas foram pensadas com base em sua relação com as características físico-espaciais dos geomorfossítios. Como exemplo o emprego do squeeze para o Alpes "O Buriti”, devido à presença de uma fonte de água mineral no local, e, para a Furna da Quitéria e o Sucavão por estarem em áreas em que se faz necessário o uso de trilhas e consequente maior ingestão de líquidos. Os folders e guia de bolso, por exemplo, 
não foram sugeridos, para o Afloramento de diabásio, principalmente por conta da sua localização, tendo sua divulgação atrelada em outras estratégias.

No que se refere às estratégias, o roteiro geológico-geomorfológico, o website e as contas (perfis) em redes sociais podem ser utilizados para todos os geomorfossítios investigados, de maneira que tais estratégias podem englobar os geomorfossítios (Fig. 4). Referente às demais estratégias, estas foram direcionadas para cada geomorfossítio de modo que represente os outros, haja vista o tamanho desse escrito.

Figura 4 - Estratégias integradas de divulgação e valorização dos geomorfossítios na microrregião de Picos/PI. A: website; B: perfil em rede social; C: roteiro geoturístico.

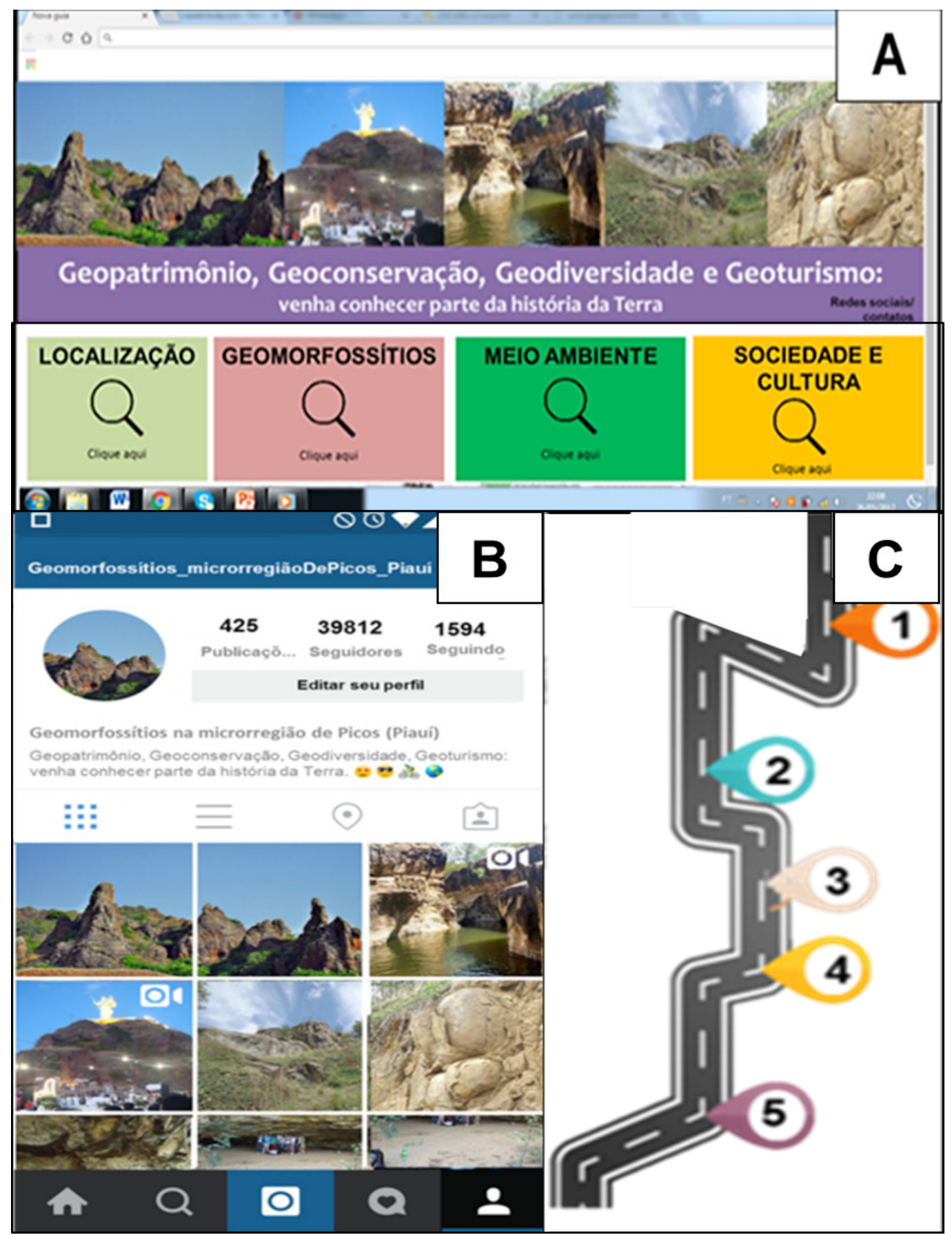

Fonte: os autores. 
Sobre a criação do website (Fig. 4A), este deverá ter como intuito evidenciar o potencial da área, com foco no aspecto geomorfológico, podendo ainda englobar os temas de meio ambiente, sociedade, cultura, redes sociais associadas, localização geográfica, geoprodutos, dentre outros. Indica-se ainda a criação de menus para download de obras relativas à temas como geodiversidade, patrimônio geomorfológico, geoturismo e geoconservação, além de abas para a divulgação de eventos científicos sobre as tais temáticas e demais destinos geoturísticos no estado e no país, bem como demais menus que se fizerem necessários. As informações sobre as características de cada geomorfossítios poderão ser acessadas a partir do clique sobre a imagem dos mesmos, o que favorecerá ampla divulgação sobre a área, posto ser a internet uma ferramenta de vasto alcance.

Corrobora a importância de website como estratégia de divulgação Moreira (2008, p. 335) para a qual "[...] websites são importantes também porque poderão ser consultados a qualquer momento e em qualquer lugar do mundo". Destaca-se que este estudo limita-se apenas a sugestões de como poderá ser desenvolvido o website, indicando-se a sua criação e manipulação por profissional especializado em mídias eletrônicas, como o webdesigner.

A rede social indicada é o Instagram (Fig. 4B) por apresentar possibilidade de proporcionar uma maior interação entre os interessados em conhecer a área do geomorfossítio e os agentes locais, haja vista que a mesma está baseada em fotografias e vídeos de curta duração numa rede social gratuita e de fácil acesso. Além do mais, entre as ferramentas do aplicativo há diferentes formas (e efeitos) de captura de fotos além da possibilidade de inserir a localização da mesma (com o acionamento do GPS do smartphone) e poder mencionar outros assuntos e até outras áreas de espetacularidade cênica por meio de hashtags.

O trabalho de manutenção da rede social é de baixo custo, podendo utilizar apenas um aparelho de smartphone para a postagem de fotografias, vídeos, visitas e possíveis campanhas, além de auxiliar na disseminação da beleza cênica da área. Contudo, a depender do interesse e objetivos da execução, pode-se inclusive criar uma comissão específica para gerir a rede social, tendo em vista que esta estratégia de valorização e divulgação será a que alcançará o maior número de pessoas. Poderá, ainda, auxiliar na divulgação de outras áreas do estado do Piauí, de modo a auxiliar na criação (a longo prazo) de uma única página para acesso, tirar dúvidas e curiosidades sobre os geomorfossítios piauienses.

No que concerne ao roteiro geoturístico/geológico-geomorfológico (Fig. 4C), este envolve os geomorfossítios Morro do Leme (1), Alpes “O Buriti” (2), Furna da Quitéria (3), Sucavão (4) e Afloramento de diabásio (5), e engloba os municípios de Oeiras, Dom Expedito Lopes, Paquetá e Picos, acessíveis a partir da BR 316, favorecendo o desenvolvimento local na dinamização da economia e na interação da população com as atividades geoturísticas. Também pode ser verificado em uma outra escala de abrangência, principalmente a estadual, a possível inter-relação junto à ações geoturísticas de outros geomorfossítios do estado do Piauí.

O roteiro geoturístico/geológico-geomorfológico proporciona ampliar o conhecimento por parte dos visitantes, pois ao conhecer um geomorfossítio, o público já terá a sugestão de outros a serem visitados através de guias que, além de descrever e explicar as características genéticas do geomorfossítio (Quadro 2), apresentarão resumidamente 
os próximos pontos integrantes do roteiro, seguindo a sequência de visitação indicada na figura $4 \mathrm{C}$.

Quadro 2 - Características genéticas dos geomorfossítios.

\begin{tabular}{|c|c|}
\hline GEOMOFOSSÍTIOS & RESUMO DAS CARACTERÍSTICAS \\
\hline MORRO DO LEME & $\begin{array}{l}\text { Geoforma erosional em forma de mesa com estratificação horizontal, com } 205 \mathrm{~m} \text { de altitude. } \\
\text { É composta por arenitos de coloração avermelhada. Localizado em área pública, de fácil } \\
\text { acessibilidade, por estrada pavimentada e ruas calçadas. É uma geoforma panorâmica da } \\
\text { qual se tem a visão de parte da cidade de Oeiras e área de depressão em seu entorno. Possui } \\
\text { moderado estado de conservação, sendo registrados pichações e desgaste natural no local. }\end{array}$ \\
\hline ALPES “O BURITI” & $\begin{array}{l}\text { Área de relevo ruiniforme, com modelado e geoformas, majoritariamente em torres e } \\
\text { pináculos. Possui fácil acessibilidade, uma vez que está localizada à beira da BR-316. } \\
\text { A visibilidade é boa, possibilitando-se a observação de suas principais características } \\
\text { e processos modeladores. Por estar localizado em propriedade particular, possui fraca } \\
\text { deterioração, haja vista o acesso ser controlado. Destaca-se ainda a existência no local de } \\
\text { uma fonte e indústria de armazenamento de água mineral. }\end{array}$ \\
\hline $\begin{array}{c}\text { FURNA DA QUITÉ- } \\
\text { RIA }\end{array}$ & $\begin{array}{l}\text { Caverna com aproximadamente } 50 \mathrm{~m} \text { de largura, } 20 \mathrm{~m} \text { de altura e } 100 \mathrm{~m} \text { de comprimento. } \\
\text { Apesar de estar localizada em área particular, possui deterioração moderada, sendo } \\
\text { registradas pichações no local, além do desgaste natural. Possui acessibilidade moderada, } \\
\text { por meio de trilha na Caatinga. A visibilidade também é moderada, haja vista a vegetação } \\
\text { que avança em direção à entrada da caverna e baixa luminosidade em seu interior. }\end{array}$ \\
\hline SUCAVÃO & $\begin{array}{l}\text { Pequeno cânion em formação na rocha arenítica. Localizado em propriedade particular, } \\
\text { com acessibilidade moderada, por meio de estrada vicinal e trilha na Caatinga. Possui } \\
\text { boa visilidade, sendo percecpítvel os processos geomorfológicos responsáveis pela sua } \\
\text { formação e constante modificação. Seu estado de conservação é bom, havendo apenas o } \\
\text { desgaste natural. }\end{array}$ \\
\hline $\begin{array}{l}\text { AFLORAMENTO DE } \\
\text { DIABÁSIO }\end{array}$ & $\begin{array}{l}\text { Afloramentos de diabásio em forma de diques e sills localizados em área pública, no } \\
\text { povoado Fátima do Piauí, município de Picos-PI. A acessibilidade é fácil, uma vez que se } \\
\text { encontra à beira da BR } 316 \text {. Possui boa visibilidade, haja vista a inexistência de obstáculos } \\
\text { impeditivos de observar o geomorfossítio e os processos geológico/geomorfológicos nele } \\
\text { presentes, a exemplo da esfoliação esferoidal. O estado de conservação é moderado, pois, } \\
\text { além do desgaste natural, há pichaçôes no local. }\end{array}$ \\
\hline
\end{tabular}

Fonte: os autores.

Outras estratégias foram pensadas para auxiliar na divulgação do patrimônio da região, como painéis, squeeze, folders, cartão-postal e chaveiro. As mesmas colaboram ainda para o desenvolvimento local, por meio da oferta de produtos e serviços que possam suprir a potencial demanda turística da área.

Sobre os painéis (Fig. 5), sugere-se o tamanho de $120 \mathrm{~cm}$ de largura por $90 \mathrm{~cm}$ de altura, considerando sua disposição tanto horizontal como vertical. Para a base, indica-se que a mesma seja confeccionada em ferro galvanizado ou madeira envernizada e fixada a uma altura que permita a leitura por todos os visitantes, inclusive crianças e cadeirantes. Segundo Moreira (2008), esta é uma das estratégias de interpretação ambiental mais utilizadas nas unidades de conservação do Brasil. 
Figura 5 - Painel para o Morro do Leme.

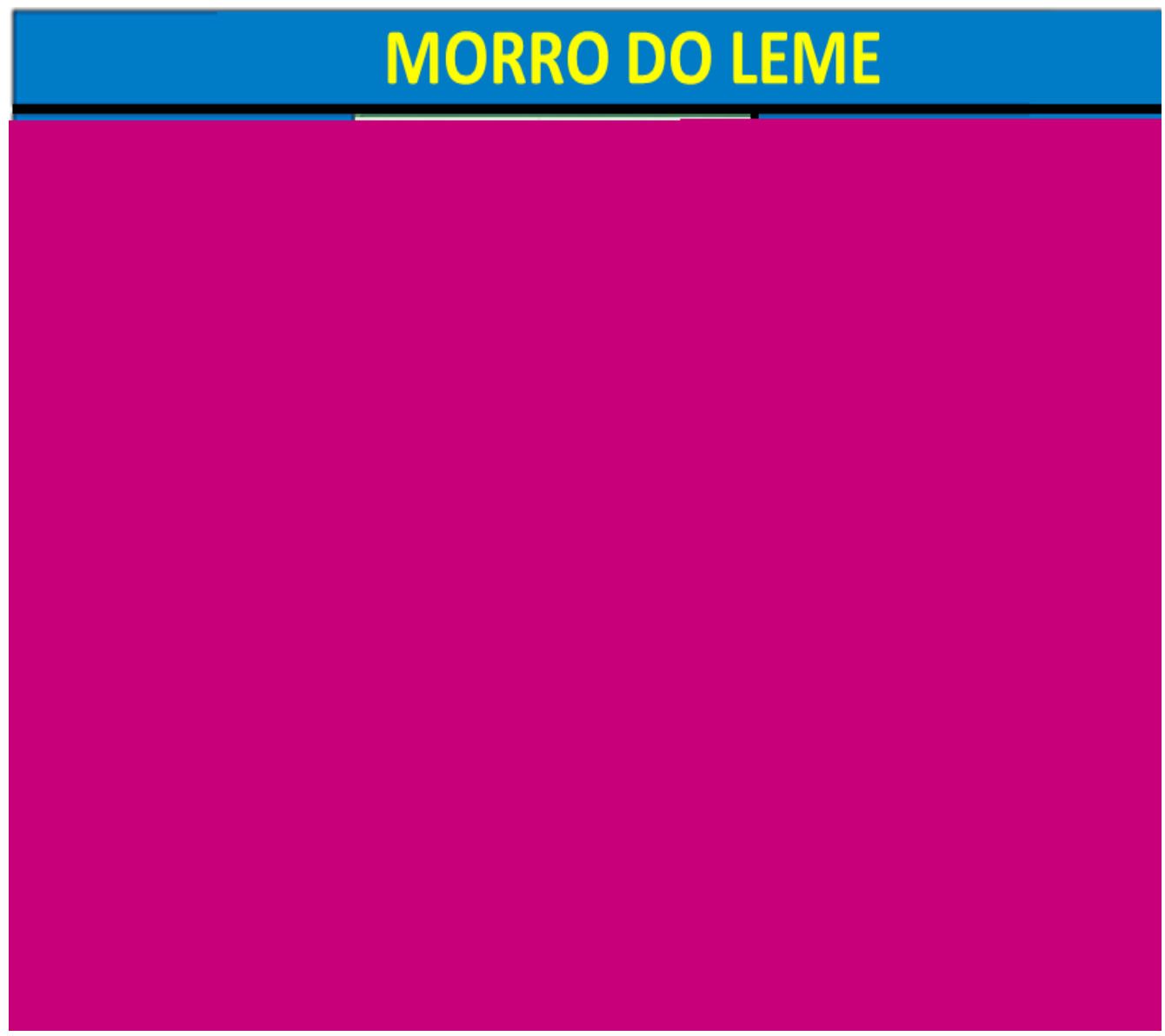

Fonte: os autores.

Na figura 6 apresenta-se proposta de squeeze e folder para o geomorfossítio Alpes "O Buriti" e para a Furna da Quitéria, ambos localizados no município de Dom Expedito Lopes. E, na figura 7, para o cartão postal (Sucavão) e o chaveiro (Afloramento de diabásio), nos municípios de Paquetá e Picos, respectivamente.

A venda de geoprodutos (chaveiros e squeeze) é outra sugestão de atividade que pode valorizar e divulgar a área, bem como representar uma fonte de renda alternativa para a comunidade local, por serem pequenas lembranças baratas do local para os visitantes, facilmente transportados.

Para os chaveiros, sugere-se a utilização de fotografias de pequena dimensão $(3 \times 4)$ inserida em material acrílico ou outro e presa a uma argola de metal. As squeezes podem ser confeccionadas em material plástico, de boa resistência, com a utilização de uma fotografia do geomorfossítio e a indicação da localização do mesmo na parte da frente.

Sobre os produtos gráficos, como folder e cartão-postal $10 \mathrm{X} 15 \mathrm{~cm}$ podem ser feitos sem grandes custos e entregues (no caso dos folders) aos visitantes e para a comunidade escolar, ou vendidos aos visitantes (no caso dos cartões-postais). 
JOSÉ FRANCISCO DE ARAÚJO SILVA ; HIKARO KAYO DE BRITO NUNES; CLÁUDIA MARIA SABÓIA DE AQUINO

Figura 6 - Proposta para: A: squeeze referente ao Alpes "O Buriti"; B: folder da Furna da Quitéria.

Fonte: os autores.

Figura 7 - Proposta para: A: cartão postal sobre o Cânion Sucavão; B: chaveiro do Afloramento de Diabásio.

Fonte: os autores. 2017. 
Propõe-se que todos os cartões-postais sigam a mesma configuração e layout a ser realizado em programas específicos para tal atividade. Indica-se que na parte da frente (Fig. 7A, parte superior) possa conter uma foto e o nome do geomorfossítio em fonte arial black, tamanho 18 pt, negrito e "calibri corpo", tamanho 11 pt, sem negrito, para o autor da foto. No verso do cartão (Fig. 7A, parte inferior), indica-se que seja inserida uma breve descrição do geomorfossítio em fonte "calibri", 12 pt, em negrito. Além disso, deve haver espaço para o selo, escrita livre pelo remetente e código postal, na lateral direita.

Para o folder, sugere-se que o mesmo seja confeccionado em folha de papel couché, ou similar, no tamanho A4 (210 X $297 \mathrm{~mm})$, na orientação paisagem, a ser dobrada em duas partes preenchidas em frente e verso, o que resultará em quatro. Na parte da frente (Fig. 6B), propõe-se a utilização de uma frase de impacto, o nome do geomorfossítio e do município onde está localizado. No verso (Fig. 6B), indica-se uma frase convidando mais pessoas para conhecerem o local e o uso de fotografias do mesmo. No interior do folder indica-se deixar claro o objetivo do folder, informar distâncias, utilizar textos sobre o geomorfossítio, geodiversidade, geopatrimônio, entre outros temas, todos em linguagem acessível a diversos públicos, curtos, com letras em cores e tamanhos de fácil leitura (Quadro 3).

Quadro 3 - Exemplo de textos que podem compor a parte interna do folder.

\section{OBJETIVO}

O objetivo principal deste folder é apresentar ao público aspectos da geodiversidade e do patrimônio geomorfológico da área em que está presente o geomorfossítio Alpes "O Buriti", com o intuito de conscientizar para a necessidade de conservação deste e demais geomorfossítios da região.

ALPES "O BURITI"

O Alpes "O Buriti" é uma área de relevo ruiniforme onde são encontradas demoiselles, alvéolos, marmitas e especialmente torres e pináculos. Resulta da escavação do arenito, oriunda de erosão pluvial e eólica, associada ao intemperismo, principalmente físico e químico.

LOCALIZAÇ̃̃O

Está localizada no município de Dom Expedito Lopes (PI) na altura do quilômetro 275 à beira da BR 316. GEOLOGIA

O geomorfossítio está inserido na Formação Cabeças do Grupo Canindé da Bacia Sedimentar do Parnaíba, sendo composto essencialmente por arenitos siltitos e folhelhos de coloração avermelhada.

GEOMORFOLOGIA

Está inserido no domínio geomorfológico da Chapada da Ibiapaba, na unidade de relevo Planalto de Inhumas. Caracteriza-se por um relevo ruiniforme de grande beleza estética em que destacam as geoformas em torres e pináculos.

\section{Fonte: os autores.}

Em Moreira (2014), a autora considera que são necessários meios, personalizados ou não, para atingir diferentes concepções quanto a proteção e divulgação desses patrimônios. Os meios não personalizados são aqueles que não utilizam diretamente pessoas (apenas objetos e/ou aparatos) como sinalização e placas indicativas, painéis interpretativos, publicações (informações impressas, livros, folhetos, guias e mapas), trilhas autoguiadas, audiovisuais, exposições, entre outros. Meios personalizados são aqueles em que há a necessidade de um intérprete ou auxiliador, como no caso de trilhas guiadas, passeios em veículos não motorizados (bicicletas, cavalos, canoas, etc.) e passeios em veículos 
motorizados, com o acompanhamento de guias, audiovisuais com atendimento pessoal, palestras, atividades como representações teatrais, jogos e simulações.

Nota-se que as estratégias sugeridas para os geomorfossítios na microrregião de Picos compõem ambos os grupos salientados, sendo algumas de caráter personalizados (roteiro geoturístico) e não personalizados (painéis, folders e guias de bolso, cartões-postais, chaveiros, squeezes, websites e contas em redes sociais), ratificando a complexidade e a dinamicidade da prática geoturística. As sugestões, no entanto, não limitam a apresentação de tantas outras, de modo que estas seriam benéficas para os geomorfossítios e ao próprio desenvolvimento local.

\section{CONCLUSÕES}

As propostas aqui sugeridas com vistas à valorização e à divulgação dos geomorfossítios na microrregião de Picos/PI são oriundas das peculiaridades, das características geomorfológicas e principalmente da potencialidade de cada estratégia, com vistas ao uso geoturístico desses locais, incentivando assim sua geoconservação.

Além disso, é preciso levar em consideração a rica geodiversidade da microrregião de Picos e o potencial geomorfológico dos geomorfossítios Morro do Leme, Alpes "O Buriti", Furna da Quitéria, Cânion Sucavão e Afloramento de diabásio, todos com uma variedade de valores estético, científico, cultural, entre outros, os quais ainda necessitam de estratégias de valorização e divulgação, bem como estudos adicionais.

Como estratégias recomenda-se: roteiro geoturístico, painéis, folders e guias de bolso, cartões-postais, squeeze, chaveiros, websites e contas em redes sociais. No entanto, é indicada a realização de estudos posteriores para que se possam traçar novas estratégias tanto para os geomorfossítio aqui salientados, quanto para outros que possam vir a serem identificados na região.

Acrescenta-se, além do mais, que os resultados podem ser alcançados a curto, médio e longo prazo, a depender da forma de execução, incentivando-se, por exemplo, o desenvolvimento sustentável da área, a manutenção do patrimônio geomorfológico e dos estudos científicos, o geoturismo e o dinamismo da economia local, subsidiados tanto pela iniciativa pública (relacionados àqueles geomorfossítios localizados em terrenos públicos) quanto pela iniciativa privada, ou mesmo público-privada (no que tange aos localizados em terrenos particulares).

Por fim, salienta-se ainda que a divulgação deve ser antecedida da construção e instalação de infraestrutura que preservem essas áreas e que ofereçam acessibilidade e segurança aos visitantes.

\section{REFERÊNCIAS}

BRILHA, José. Patrimônio geológico e geoconservação: a conservação da natureza na sua vertente geológica. Braga: Palimage, 2005. 
GARCIA, Taís da Silva. Da geodiversidade ao geoturismo: valorização e divulgação do geopatrimônio de Caçapava do Sul, RS, Brasil. Santa Maria, 2014. Dissertação (Mestrado em Geografia) - Universidade Federal de Santa Maria, UFSM.

GODOY, Leticia Hirata. Potencial Geoparque de Uberaba (MG): geodiversidade e geoconservação. Soc. \& Nat., v. 2, n. 25, 395-410, 2013.

GUIMARÃES, Thaís de Oliveira. Geoconservação: mapeamento, descrição e propostas de divulgação de trilhas geoturísticas no Parque Metropolitano Armando de Holanda Cavalcanti Cabo de Santo Agostinho/PE - Brasil. Recife, 2013. Dissertação (Mestrado em Geociências) - Universidade Federal de Pernambuco, UFPE.

LOPES, Laryssa Sheydder de Oliveira. Geoconservação e Geoturismo no Parque Nacional de Sete Cidades, Piauí. Teresina, 2011. Dissertação (Mestrado em Desenvolvimento e Meio Ambiente) - Universidade Federal do Piauí, UFPI.

MACHADO, Maria Márcia Magela; RUCHKYS, Úrsula Azevedo. Valorizar e divulgar a geodiversidade: estratégias do Centro de Referência em Patrimônio Geológico CRPG - MHNJB/UFMG. Geonomos, v. 18. n. 2, p. 53-56, 2010.

MEIRA, Suedio Alves. "Pedras que Cantam": o patrimônio geológico do Parque Nacional de Jericoacoara, Ceará, Brasil. Fortaleza, 2016. Dissertação (Mestrado em Geografia) - Universidade Estadual do Ceará, UFCE.

MOREIRA, Jasmine Cardozo. Patrimônio geológico em Unidades de Conservação: atividades interpretativas, educativas e geoturísticas. Florianópolis, 2008. Tese (Doutorado em Geografia) Universidade Federal de Santa Catarina, UFSC.

Geoturismo e interpretação ambiental. Ponta Grossa: Ed. UEPG, 2014.

MOURA-FÉ, Marcelo Martins. Geoturismo: uma proposta de turismo sustentável e conservacionista para a Região Nordeste do Brasil. Soc. \& Nat., Uberlândia, v. 27, n. 1, p. 53-66, 2015.

PEREIRA, P. J. S. Patrimônio geomorfológico: conceptualização, avaliação e divulgação - aplicação ao Parque Nacional de Montesinho. Braga, 2006.395f. Tese (Doutorado em Ciências - Geologia) - Universidade do Minho.

PIEKARZ, Gil Francisco; LICCARDO, Antonio. Painéis geoturísticos e geodidáticos. In: LICCARDO, Antonio; GUIMARÃES, Gilson Burigo (Orgs.). Geodiversidade na Educação. Ponta Grossa: StudioTexto, 2014.

OLIVEIRA, Paula Cristina Almeida. Avaliação do patrimônio geomorfológico potencial dos municípios de Coromandel e Vazante, MG. Uberlândia, 2015. Tese (Doutorado em Geografia) - Universidade Federal de Uberlândia, UFU.

SANTOS, Edjane Maria dos. A Geoconservação como ferramenta para o desenvolvimento sustentável em regiões semiáridas: estudo aplicado à Mesorregião do agreste de Pernambuco, Nordeste do Brasil. Recife, 2016. Tese (Doutorado em Geociências) - Universidade Federal de Pernambuco, UFPE.

SILVA, Brenda Rafaele Viana; BAPTISTA, Elisabeth Mary de Carvalho. Roteiro geológico-geomorfológico litoral piauiense: caminhos para a geoconservação. Revista Geonorte, v. 4, v.10, n.1, 2014.

SILVA, José Francisco de Araújo et al. Identificação de geomorfossítios na Microrregião de Picos-PI. In: SIMPÓSIO BRASILEIRO DE GEOGRAFIA FÍSICA APLICADA, 17, 2017, Campinas. Anais... Campinas, 2017. p. 3042-3053.

Geodiversidade e patrimônio geológico / geomorfológico das "Cidades de Pedras" - Piauí: potencial turístico e didático. Teresina, 2017. Dissertação (Mestrado em Geografia) - Universidade Federal do Piauí, UFPI.

VASQUEZ, Lúcia Maria de Jesus. Estratégia de valorização de geossítios no Geoparque Arouca. Minho, 2010. Dissertação (Mestrado em Património Geológico e Geoconservação) - Universidade do Minho, Portugal.

Data de submissão: 14/fev./2018

Data de aceite: $10 /$ jul./2018 